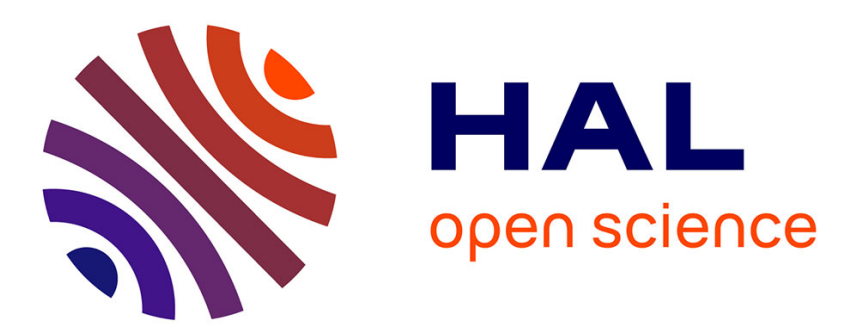

\title{
Improved evaluation of cover crop species by growth and root factors
}

\author{
G. Bodner, M. Himmelbauer, W. Loiskandl, H.-P. Kaul
}

\section{To cite this version:}

G. Bodner, M. Himmelbauer, W. Loiskandl, H.-P. Kaul. Improved evaluation of cover crop species by growth and root factors. Agronomy for Sustainable Development, 2010, 30 (2), 10.1051/agro/2009029. hal-00886527

\section{HAL Id: hal-00886527 \\ https://hal.science/hal-00886527}

Submitted on 1 Jan 2010

HAL is a multi-disciplinary open access archive for the deposit and dissemination of scientific research documents, whether they are published or not. The documents may come from teaching and research institutions in France or abroad, or from public or private research centers.
L'archive ouverte pluridisciplinaire HAL, est destinée au dépôt et à la diffusion de documents scientifiques de niveau recherche, publiés ou non, émanant des établissements d'enseignement et de recherche français ou étrangers, des laboratoires publics ou privés. 


\title{
Improved evaluation of cover crop species by growth and root factors
}

\author{
G. BODNER $^{1 *}$, M. HIMMELBAUER ${ }^{2}$, W. LOISKANDL ${ }^{2}$, H.-P. KAUL ${ }^{1}$ \\ ${ }^{1}$ Institute of Agronomy and Plant Breeding, Department of Applied Plant Sciences and Plant Biotechnology, University of Natural Resources and Applied Life \\ Sciences Vienna, Gregor Mendel Straße 33, 1190 Vienna, Austria \\ ${ }^{2}$ Institute of Hydraulics and Rural Water Management, Department of Water, Atmosphere and Environment, University of Natural Resources and Applied Life \\ Sciences Vienna, Muthgasse 18, 1190 Vienna, Austria
}

(Accepted 20 July 2009)

\begin{abstract}
Cover crops are plants that are integrated in the crop rotation between two cash crops. The main objectives of cover cropping are organic matter input, mitigation of nitrate leaching and reduction of soil erosion. These benefits will only be achieved efficiently if the selected cover crop species are adapted to local environmental conditions and appropriate for the defined agro-ecological target. Therefore, a main limitation in cover cropping is the lack of a comprehensive species description. An improved cover crop characterization could be achieved with quantitative parameters derived from growth functions. Here, we show the use of this approach to assess plant traits relevant for erosion control by cover cropping. An experiment with four cover crop species (phacelia, vetch, rye and mustard) was performed over two years at a semi-arid site in Eastern Austria. Canopy cover was measured four times over the vegetation period. Root length density measurements were made to $40 \mathrm{~cm}$ soil depth before winter. Canopy dynamics were characterized by parameters from the asymptotic Gompertz function and from an extended logistic model that includes a parameter for decay after maximum coverage. Our results show that vetch had the lowest early vigor after dry conditions at sowing, with $+45 \%$ longer time to attain maximum growth rate (parameter $t_{\max }$ ) than the other species. Drought during the later autumn growing period led to the highest reduction in maximum canopy cover (parameter $\mathrm{y}_{\max }$ ) for phacelia $(-41 \%)$. The rooting pattern was assessed by parameters from the exponential distribution function of Gerwitz and Page. The most intense rooting near the soil surface (parameter $\mathrm{L}_{0}$ ) was found for phacelia $\left(9.7 \mathrm{~cm} \mathrm{~cm}^{-3}\right)$. Vetch had the lowest $\mathrm{L}_{0}\left(4.6 \mathrm{~cm} \mathrm{~cm}^{-3}\right)$ but highest root allocation to deeper soil layers. Mustard combined high average values in $\mathrm{y}_{\max }(76 \%)$ and $\mathrm{L}_{0}\left(6.3 \mathrm{~cm} \mathrm{~cm}^{-3}\right)$ with a stable growth over both years. The potential strengths of phacelia and vetch were more dependent on the particular year. Rye showed a stably high $\mathrm{L}_{0}\left(8.6 \mathrm{~cm} \mathrm{~cm}^{-3}\right)$, but had only a low average value of $\mathrm{y}_{\max }(55.1 \%)$. The quantitative parameter sets we derived for plant traits required for erosion control improved cover crop comparison and analysis of their local adaptation. Based on this extended species description our approach allows a better evaluation of cover crops and can be used for the optimization of management and decision support.
\end{abstract}

cover crops / growth functions / species description / rooting pattern / rainfall distribution

\section{INTRODUCTION}

Cover cropping is a widely used agro-environmental practice to reduce negative effects of post-harvest fallowing during autumn and winter. Cover crops reduce nitrate leaching (e.g. Thorup-Kristensen, 2001; Vidal and Lopez, 2005, Rinnofner et al., 2008) and improve soil physical properties (MacRae and Mehuys, 1985). Both living crops and mulch cover protect the soil surface from the impact of raindrops and can reduce runoff and soil erosion by more than $95 \%$ compared with fallow (e.g. Meyer et al., 1999; Zuazo and Pleguezuelo, 2008). Quinton et al. (1997) studied the impact of increasing canopy coverage on soil loss. They found that the greatest reduction occurred for canopy covers greater than $30 \%$ with a maximum reduction reached when $70 \%$ of the soil was covered by vegetation.

*Corresponding author: gernot.bodner@boku.ac.at
Besides soil cover, the cover crop root system is of particular importance to improve soil quality parameters such as biological activity (Schutter and Dick, 2002), aggregate stability (Liu and Bomke 2005) and hydraulic properties (Carof et al., 2007; Bodner et al., 2008). Furthermore, a high and stable aboveground growth needs sufficient water and nutrient supply via the root system.

While previous research mainly focused on effects of cover crops in relation to environmental or agronomic parameters, there is a lack of studies that provide a detailed characterization of the available cover crop species themselves. However, the quantification of cover crop growth dynamics is essential for the optimization of their management to obtain the desired agro-environmental effects.

Different mathematical functions with biologically meaningful parameters have been used to describe growth processes 


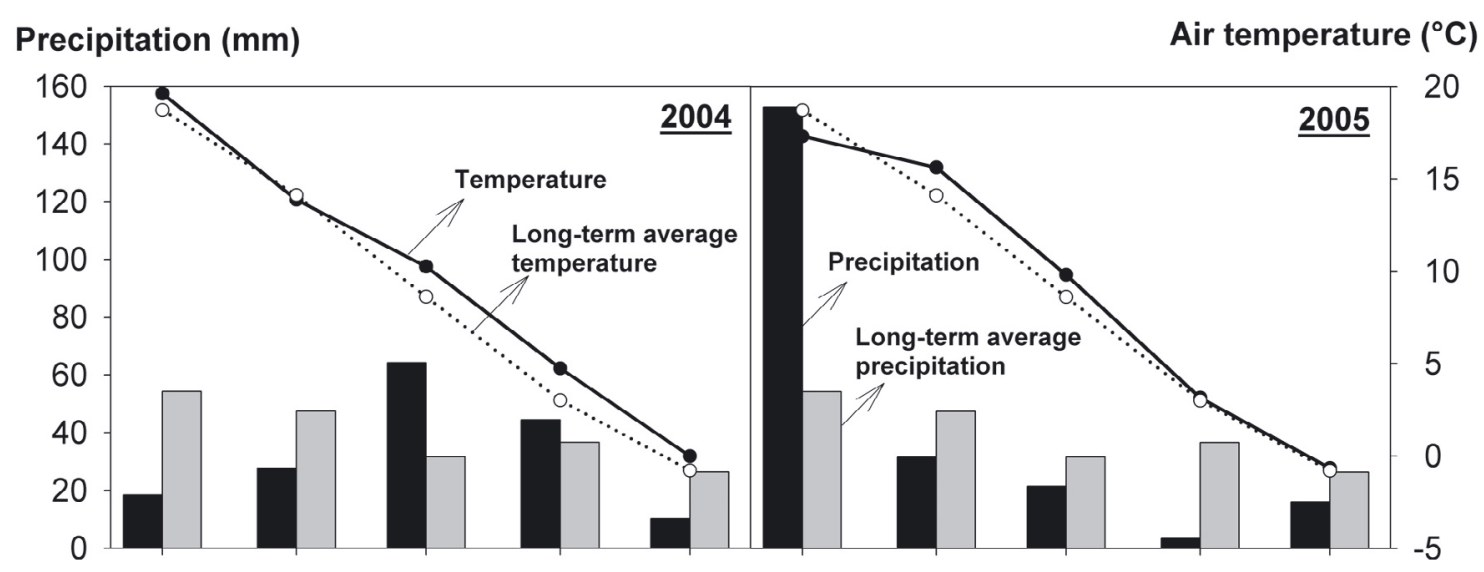

Figure 1. Temperature and precipitation during the field experiment compared with the long-term (30 years) averages, with high (2004) vs. low (2005) rainfall at cover crop seeding in August and regular (2004) vs. irregular (2005) rainfall during the autumn growing period.

(e.g. Werker and Jaggard, 1997) and root distribution (e.g. Feddes and Raats, 2004). Based on the model parameters, differences between plant species can be characterized quantitatively and environmental influences on growth performance can be studied. This study presents an approach for improved characterization of cover crop species based on parameters from plant growth and root distribution functions. The approach is used to assess canopy coverage and rooting traits of different cover crop species, which are two important properties of cover crop plants in relation to erosion control. We analyze the sensitivity of the species in terms of these traits for two years of contrasting rainfall pattern under semi-arid conditions. This exemplifies the use of quantitative approaches in species description, to obtain more targeted recommendations of appropriate cover crop species and ensure their agroenvironmental benefits.

\section{MATERIAL AND METHODS}

\subsection{Study site and experimental set-up}

The data used for the present study are from a field experiment in the pannonic region of Eastern Austria $\left(48^{\circ} 12^{\prime} \mathrm{N}\right.$ and $\left.16^{\circ} 34^{\prime} \mathrm{E}\right)$. Climatically the site is characterized by semi-arid conditions with an average annual precipitation of $491 \mathrm{~mm}$, a mean annual temperature of $9.1^{\circ} \mathrm{C}$, an average wind speed of $3 \mathrm{~m} \mathrm{~s}^{-1}$ and an average global radiation of $17.1 \mathrm{MJ} \mathrm{m}^{-2}$. The experiment is located on a sloping chernozem soil with a silt content between 45.5 and $50.4 \%$. Due to these characteristics the field is susceptible to soil erosion and therefore representative of sites where cover cropping is typically used to avoid soil degradation.

Weather data were recorded by an automated ADCON weather station at the experimental field. Two consecutive years were evaluated. They showed distinct differences in weather conditions. Such differences are typically found during the cover crop vegetation period in the pannonic climate. Figure 1 shows mean precipitation and temperature compared with the long-term averages for the cover crop growing period in both years.

The field experiment consisted of four cover crops from different plant families and with different root characteristics. Phacelia (Phacelia tanacetifolia Benth. cv. Vetzrouska) is a non-winter-hardy cover crop from the Hydrophyllaceae family with a taproot system concentrated in the upper soil (Hampl, 1996). Hairy vetch (Vicia villosa L. cv. Beta) is a winter-hardy legume species with a primary root branching into several lateral roots of similar diameter (Kutschera et al., 2009). Rye (Secale cereale L. cv. Picasso) is also a winterhardy cover crop with the typical dense adventitious root system of grasses (Kutschera et al., 2009). Mustard (Sinapis alba L. cv. Caralla) is a non-winter-hardy Brassicacea species with a strong taproot (Hampl, 1996). Seeding rates were $10 \mathrm{~kg} \mathrm{ha}^{-1}$ for phacelia, $90 \mathrm{~kg} \mathrm{ha}^{-1}$ for vetch, $120 \mathrm{~kg} \mathrm{ha}^{-1}$ for rye and $10 \mathrm{~kg} \mathrm{ha}^{-1}$ for mustard. In accordance with the Austrian agroenvironmental program ÖPUL, cover crops were sown on 20 August. Plots $\left(60 \mathrm{~m}^{2}\right)$ were arranged in a randomized complete block design with three replications. Cover crops followed barley in both years. Management of the main crop was the same in all plots. The main crop was fertilized with $50 \mathrm{~kg}$ $\mathrm{N} \mathrm{ha}^{-1}$ while the cover crops did not receive any fertilization. For the present study, the focus was on the main growing period of the cover crops from seeding until December, when the non-winter-hardy species were killed by frost.

\subsection{Canopy cover measurements}

Canopy cover of the crops was measured four times during the growing period by image analysis of digital pictures according to Karcher and Richardson (2005). Three digital photos were taken per plot from a constant height of one meter above the ground. Image analysis for percent ground cover was performed based on color discrimination using the software SigmaScan Pro5. Additionally, aboveground dry matter of the cover crops was measured on the last canopy cover sampling date from a sample area of $1 \mathrm{~m}^{2}$. 


\subsection{Root sampling and analysis}

Root samples were taken using the soil core method (Böhm, 1979) in mid-December at the end of the cover crop vegetation period when the plants were likely to have reached their maximum growth before winter. The auger used for sampling had an inner diameter of $7 \mathrm{~cm}$. Due to limited auger length, sampling depth was restricted to the upper $40 \mathrm{~cm}$. However, this can be expected to cover the soil layers where most roots are concentrated and therefore allow a sufficient description of cover crop rooting traits with relevance for soil structure. Two soil cores were taken per plot, one directly below the plant and one between two rows. The samples $\left(1540 \mathrm{~cm}^{3}\right)$ were then divided into three sub-samples from $0-10 \mathrm{~cm}, 10-20 \mathrm{~cm}$ and $20-40 \mathrm{~cm}$ soil depth. The procedure of root length measurement is described in detail by Himmelbauer et al. (2004). In short, roots were separated from soil by a hydro-pneumatic elutriator and debris as well as dead roots were removed from the samples. Root length was then measured by image analysis of stained roots using WinRhizo 4.1 (Régent Instruments, Quebec).

\subsection{Growth models for canopy cover}

Two model approaches were used to derive parameters characterizing the growth pattern of cover crop canopies. The classical Gompertz function assumes an asymptotic growth to a maximum coverage and is given by (e.g. Pegelow et al., 1977):

$$
\mathrm{y}_{\mathrm{i}}=\mathrm{y}_{\max , \mathrm{G}} \exp \left\{-\exp \left(\mathrm{k}_{\mathrm{G}}\left(\mathrm{t}_{\mathrm{i}}-\mathrm{t}_{\mathrm{max}, \mathrm{G}}\right)\right)\right\}
$$

where $\mathrm{y}_{\mathrm{i}}(\%)$ is ground cover at day $\mathrm{t}_{\mathrm{i}}(\mathrm{d})$ after sowing, $\mathrm{y}_{\max , \mathrm{G}}(\%)$ is the maximum coverage, $\mathrm{k}_{\mathrm{G}}$ is the growth rate $\left(\mathrm{d}^{-1}\right)$ and $\mathrm{t}_{\max , \mathrm{G}}(\mathrm{d})$ is the time until growth rate is maximum.

Frequently, a decrease in canopy cover from a maximum value can be observed due to leaf wilting or senescence. Werker and Jaggard (1997) presented a modification of the Gompertz model by including a decay term. The model is given by:

$$
\mathrm{y}_{\mathrm{i}}=\mathrm{y}_{\max , \mathrm{WJ}} \exp \left(\mu_{\min }\left(\mathrm{t}_{\mathrm{i}}-\mathrm{t}_{\mathrm{max}, \mathrm{WJ}}\right)-\frac{\mu_{\mathrm{min}}}{\mathrm{k}_{\mathrm{WJ}}}\left(1-\mathrm{e}^{-\mathrm{k}_{\mathrm{WJ}}\left(\mathrm{t}_{\mathrm{i}}-\mathrm{t}_{\max , \mathrm{WJ}}\right)}\right)\right)
$$

where $\mathrm{y}_{\max , \mathrm{WJ}}(\%)$ again is the maximum coverage, $\mu_{\min }\left(\mathrm{d}^{-1}\right)$ is the decay rate, $t_{\max , W J}(d)$ in this case is the time until ground cover reaches its maximum and $\mathrm{k}_{\mathrm{WJ}}\left(\mathrm{d}^{-1}\right)$ is the rate that determines how fast the initial growth approaches $\mu_{\min }$.

\subsection{Root distribution function}

Using measured root length density data, root distribution was characterized by the exponential function of Gerwitz and Page (1974), which describes the decrease in rooting density with depth by:

$$
\mathrm{RLD}_{\mathrm{i}}=\mathrm{L}_{0} \mathrm{e}^{-\mathrm{az}_{\mathrm{i}}}
$$

where $\operatorname{RLD}_{\mathrm{i}}\left(\mathrm{cm} \mathrm{cm}^{-3}\right)$ is root length density at soil depth $\mathrm{Z}_{\mathrm{i}}(\mathrm{cm}), \mathrm{L}_{0}\left(\mathrm{~cm} \mathrm{~cm}^{-3}\right)$ is root length density at the soil surface $(\mathrm{z}=0)$ and a (dimensionless) is a parameter describing the decrease in root length density with depth.

\subsection{Data analysis, calculation and evaluation of distinctive plant parameters}

The evaluation of measurements followed the stepwise approach used by Schabenberger and Pierce (2002) for the analysis of factorial experiments with non-linear response. In a first step, the whole data set was submitted to a mixed model analysis of variance using PROC MIXED in the SAS software package. The correlation structure among repeated measurements in the statistical analysis was described by a first-order autoregressive model (Piepho et al., 2004). The objective of the initial analysis of variance was to derive the factors of major influence (i.e. year, species, block and measurement date in the case of canopy cover). This identifies those subsets of the whole data set that differ significantly from each other and thus require a separate growth model for their proper characterization.

The subsequent description of the data subsets was done by curve fitting of growth (Eqs. (1) and (2)) and root distribution functions (Eq. (3)) using non-linear regression by the SAS procedure PROC NLIN.

In the case of canopy cover, the two different growth functions (Eqs. (1) and (2)) were first evaluated concerning their general appropriateness to describe the respective data sets. When both functions provided a significant fit with a unique parameter set, their appropriateness was decided using the Akaike Information Criterion (AIC) as a goodness of fit parameter.

The subsequent analysis of the parameters from the fitted growth functions was performed with respect to (i) their distinctiveness between the four cover crop species and (ii) their stability over the two years for each crop species. As there was no common growth function shared by all data sets (cf. Sect. 3.2) and thus no possibility of a single ANOVA-based analysis incorporating both effects (species and year), two different approaches were used to answer the respective questions.

The distinctiveness of model parameters between the cover crop species was determined by common ANOVA and least significant differences (LSD). The analysis was done separately for each year. This is justified because (i) the initial analysis of variance indicated significant year differences, and consequently (ii) only within one year did cover crop species share a common growth model.

The second question, i.e. growth performance stability of each cover crop species over the two years, required the definition of a common growth model shared by the respective species in both years. The decision on the adequate model for each species was taken based on the Akaike Information Criterion (AIC). For the subsequent evaluation of the intra-species parameter sensitivity to the year, a sum of squares reduction test (SSR-test) was chosen. This approach is suitable as the 
species-wise comparison of growth performance is only targeting the year effect and does not imply any interaction effect (Schabenberger and Pierce, 2002). The SSR test statistically compares a "full model" where all parameters are year-specific with the same model sharing one or several common parameter values over both years. Shared parameter values express a stable growth performance in the respective trait. The comparison is done stepwise starting with a completely reduced model (i.e. no difference in all growth parameters between the years) and successively allowing for an increasing number of year-specific parameters. The process is stopped at the number of fixed parameters where no significant difference occurs between the full and reduced model at $P<0.05$. This final model reveals sensitive and non-sensitive growth parameters of the respective cover crop species. The F-value for the statistical test is given by:

$$
\mathrm{F}=\frac{\frac{\mathrm{RSS}_{\mathrm{r}}-\mathrm{RSS}_{\mathrm{f}}}{\mathrm{df}_{\mathrm{f}}-\mathrm{df}_{\mathrm{r}}}}{\frac{\mathrm{RSS_{ \textrm {f } }}}{\mathrm{df}_{\mathrm{res}, \mathrm{f}}}} \quad P=\operatorname{Pr}\left(\mathrm{F}_{\mathrm{df}_{\mathrm{f}}-\mathrm{df}_{\mathrm{r}}, \mathrm{df}_{\mathrm{res}, \mathrm{f}}} \geqslant \mathrm{F}\right)
$$

where $\mathrm{RSS}_{\mathrm{r}}$ is the residual sum of squares of the reduced model, $\mathrm{RSS}_{\mathrm{f}}$ is the residual sum of squares of the full model, $\mathrm{df}_{\mathrm{f}}$ and $\mathrm{df}_{\mathrm{r}}$ are the model degrees of freedom of the full and reduced model, respectively, and $\mathrm{df}_{\mathrm{res}, \mathrm{f}}$ are the error degrees of freedom of the full model. The resulting F-value is compared with the tabulated F-value at $\left(\mathrm{df}_{\mathrm{f}}-\mathrm{df}_{\mathrm{r}}\right)$ numerator degrees of freedom and $\mathrm{df}_{\text {res, } \mathrm{f}}$ denominator degrees of freedom, giving the probability level $P$.

The rooting system was analyzed using the root distribution function parameters of equation (3). Again, evaluation of species' distinctiveness in root parameters was performed by common ANOVA and least significant differences, while year stability/plasticity in the rooting pattern of the individual cover crops was assessed using a SSR test.

\section{RESULTS AND DISCUSSION}

A field experiment was performed in order to develop an improved quantitative method for the evaluation of different cover crop species. The performance of four cover crops (phacelia, vetch, rye and mustard) was studied over two years, in terms of their canopy coverage and rooting density, two important plant traits for erosion control and soil structure stabilization. Using measured data for these two plant variables, quantitative parameters were derived from growth and root distribution functions to assess the vigor and the stability of the investigated species under the local semi-arid conditions.

\subsection{Climatic characteristics of the growing periods}

The two experimental years showed substantial differences in their climatic growing conditions during the cover crop vegetation period, particularly in relation to rainfall distribution (Fig. 1). In 2004, dry conditions occurred at the time of seeding and germination of the cover crops. August precipitation was $66 \%$ lower compared with the long-term average. During the later cover crop growing period from mid-September to mid-November there was regular rainfall. In 2005, by contrast, August was characterized by very high precipitation, accounting for $67 \%$ of the total rainfall during the cover crop vegetation period before winter. After the 29 September until 5 December, only $11 \mathrm{~mm}$ of rain fell, resulting in severely dry conditions during the main cover crop growing period. In 2004 the climatic water balance deficit (cumulative rainfall minus cumulative potential evapotranspiration) was $-132.4 \mathrm{~mm}$. This high deficit resulted from the dry conditions until mid-September when the evaporative demand of the atmosphere was still high. In 2005 the cumulative deficit was lower $(-19.2 \mathrm{~mm})$. However, between October and December the low rainfall resulted in a continuously negative balance between precipitation and evapotranspiration.

\subsection{Growth function performance}

The analysis of variance of canopy cover data indicated a significant interaction between year $\times$ sampling date $\times$ cover crop $(P=0.02)$. This defines the data subsets for nonlinear fitting to consist of year-wise cover crop-specific growth curves (Fig. 2).

It should be noted that high standard errors in 2004 reflect a pronounced inhomogeneity of the stands, which developed from suboptimal dry soil conditions at seedbed preparation. At the toe-slope of the experimental field, with higher clay content, this resulted in clods, and consequently a poor seed-soil contact. The subsequent delay in emergence and early growth at the toe-slope was not regained during the entire growing period.

The three-parameter Gompertz model gave a satisfactory description of canopy growth for all cover crops in 2004. In 2005 the Werker \& Jaggard function was required to capture the observed final decay. For vetch, with a delayed onset of growth and a sustained increase in canopy cover until the final observation date before winter, the Werker \& Jaggard model did not converge in 2004. In 2005 the Gompertz model did not fit for rye due to the large final decrease, as well as for mustard due to early reduction in soil cover from the maximum that was reached already in October. For those species where both growth models showed a significant fit (i.e. 2004: phacelia, rye and mustard; 2005: phacelia and vetch), the more suitable model was decided based on the value of the Akaike Information Criterion (AIC) as a statistical parameter for fitting quality. The AIC indicated that the Gompertz logistic curve fitted better for all cover crops in 2004, while the growing pattern of 2005 was better described by the growth and decay function of Werker \& Jaggard. The two years differed substantially in the time until crop emergence. For the ANOVA evaluation of year effects on canopy cover at a given date, measurements were taken at similar times after sowing. From the point of view of growth model fitting, however, differentiated measurement dates would have been preferable, mainly in the early growing period. 


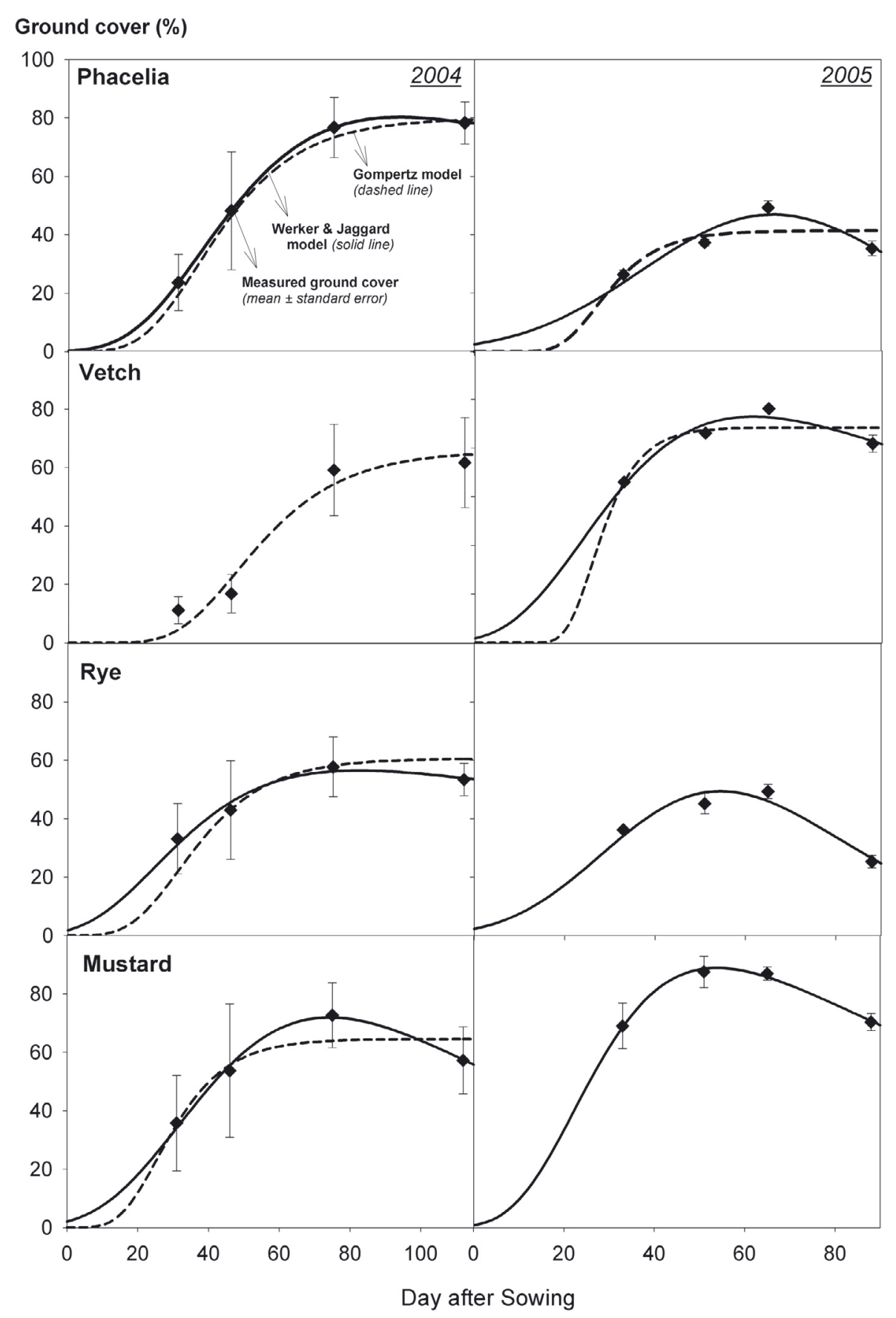

Figure 2. Growth functions fitted to the measured ground cover (means \pm standard error) of different cover crop species and in two years of contrasting rainfall pattern. The asymptotic Gompertz model describes the observed dynamics accurately, except for those cases where drought induced a substantial final reduction of canopy cover in 2005. These cases required an additional decrease parameter in the function (Werker \& Jaggard model).

Several empirical functions are available to characterize the logistic growth dynamics that are frequently observed in nature (e.g. Tsoularis and Wallace, 2002). Werker and Jaggard (1997) extended some of these functions to include a decreasing branch after the maximum in order to analyze phenomena such as the effects of drought, disease or herbicide damage on the plant canopy. These extended models therefore include an additional parameter for decay. The higher complexity of the model may increase stability problems of the iterative parameter estimation procedure, mainly related to the selection of adequate initial values (Robert et al., 1999; Schabenberger and Pierce, 2002; Yin et al., 2003). The growth functions used in our study (Gompertz model and extended Gompertz model by Werker \& Jaggard) were fitted with a Marquardt algorithm 
Table I. Estimated parameter values (with standard errors in parentheses) of the Gompertz model describing the growth of canopy coverage of different cover crops in 2004. For significant effects in the ANOVA at $P<0.05$, comparison of means is indicated by lowercase letters. Those species sharing the same letters are not significantly different.

\begin{tabular}{lccc}
\hline & $\mathrm{y}_{\max , \mathrm{G}}(\%)$ & $\mathrm{t}_{\max , \mathrm{G}}(\mathrm{d})$ & $\mathrm{k}_{\mathrm{G}}\left(\mathrm{d}^{-1}\right)$ \\
\cline { 2 - 4 } Phacelia & $79.9(7.0)$ & $36.4(3.8) \mathrm{a}$ & $0.098(0.048)$ \\
Vetch & $64.1(8.9)$ & $47.9(5.2) \mathrm{b}$ & $0.091(0.024)$ \\
Rye & $60.6(3.1)$ & $31.3(4.4) \mathrm{a}$ & $0.073(0.023)$ \\
Mustard & $72.1(6.4)$ & $32.5(3.7) \mathrm{a}$ & $0.161(0.081)$ \\
\cline { 2 - 4 } & $P=0.17$ & $P=0.03$ & $P=0.61$ \\
\hline
\end{tabular}

Legend: $\mathrm{y}_{\max , \mathrm{G}}=$ maximum canopy coverage, $\mathrm{k}_{\mathrm{G}}=$ growth rate, $\mathrm{t}_{\mathrm{max}, \mathrm{G}}=$ time until maximum growth rate (Eq. (1)).

in PROC NLIN of SAS. Although only a limited number of measurement points were available from the field experiment, the iteration method converged for all cases. The uniqueness of the parameter estimates was further tested by using different initial values. The same parameter values were obtained. This indicated that the iteration algorithm indeed converged at a global minimum (Schabenberger and Pierce, 2002).

From the point of view of cover crop species characterization for soil protection, parameters that describe the early vigor in surface coverage and the total canopy growth potential in autumn are most relevant. The additional information of the Werker \& Jaggard model shows differences in the sensitivity to adverse conditions, such as drought, which lead to some canopy decrease in the late season. A slight canopy reduction in the late season, however, is less important in the context of erosion control by cover cropping. A sufficiently high surface cover is generally maintained by the living canopy and mulch of falling leaves.

A more detailed analysis of cover crop interactions with the environment would suggest the use of mechanistic growth models. However, such models require a large number of measurement data for an accurate parameterization of the modeled plant-soil-atmosphere system and validation of simulation results. This need for multiple parameters is a constraint of mechanistic models compared to a growth function analysis. In comparative species description, it must be possible to evaluate a large number of species and sites (multi-location trials). This imposes a limit on measurement frequency and detail. Therefore, we consider growth functions that can be easily parameterized with sufficient accuracy as most adequate for this purpose.

\subsection{Comparison of canopy coverage dynamics between different cover crops}

The model parameters of the fitted functions were subsequently analyzed for inter-specific differences between the cover crops. Tables I and II show the results of the analysis of variance for differences between the species in the Gompertz parameters for 2004 and the Werker \& Jaggard's parameters for 2005 , respectively.
Table II. Estimated parameter values (with standard errors in parentheses) of the Werker \& Jaggard's model parameters describing the growth of canopy coverage of different cover crops in 2005. For significant effects in the ANOVA at $P<0.05$, comparison of means is indicated by lower-case letters. Those species sharing the same letters are not significantly different.

\begin{tabular}{|c|c|c|c|c|}
\hline & $\mathrm{y}_{\max , \mathrm{WJ}}(\%)$ & $\mathrm{t}_{\max , \mathrm{WJ}}(\mathrm{d})$ & $\mu_{\min }\left(\mathrm{d}^{-1}\right)$ & $\mathrm{k}_{\mathrm{WJ}}\left(\mathrm{d}^{-1}\right)$ \\
\hline Phacelia & $47.0(5.3) \mathrm{a}$ & $66.1(6.2)$ & $-0.197(0.042) \mathrm{a}$ & $0.006(0.003)$ \\
\hline Vetch & $93.5(2.1) \mathrm{b}$ & $62.8(3.8)$ & $-0.011(0.001) \mathrm{c}$ & $0.052(0.014)$ \\
\hline Rye & $49.6(4.6) \mathrm{a}$ & $54.0(5.7)$ & $-0.061(0.014) \mathrm{ab}$ & $0.023(0.008)$ \\
\hline \multirow[t]{2}{*}{ Mustard } & $76.8(1.2) \mathrm{b}$ & $45.9(1.8)$ & $-0.034(0.003) b c$ & $0.131(0.017)$ \\
\hline & $p<0.01$ & $P=0.14$ & $P=0.02$ & $P=0.08$ \\
\hline
\end{tabular}

Legend: $\mathrm{y}_{\max , \mathrm{WJ}}=$ maximum canopy coverage, $\mathrm{t}_{\max , \mathrm{WJ}}=$ time until maximum canopy coverage, $\mu_{\min }=$ decay rate, $\mathrm{k}_{\mathrm{WJ}}=$ growth rate (Eq. (2)).

Foley (1999) suggested rapid emergence and vigorous early growth under a wide range of environmental conditions as an important breeding objective for cover crops. This is particularly important at sites with potential soil moisture shortage after cash crop harvest. This was the case in 2004 in our study, when susceptible species could be substantially impaired in their early stages. In this year cover crops differed significantly in $t_{\max , G}$, the time to reach the maximum growth rate, $\mathrm{k}_{\mathrm{G}}$. Vetch had a $t_{\max , G}$ that was 15 days longer compared with the average duration for the other species ( $33 \mathrm{~d}$ ). Clark (2007) pointed out that dry conditions could reduce germination and retard early growth of vetch. This can be related to a higher seed weight of vetch compared with the other species investigated and thus more water required to initiate germination.

Besides the characteristic delay of vetch to reach its maximum growth rate, there was no distinct inter-species variability in canopy cover dynamics under conditions of regular rainfall during the autumn growing period. All crops achieved a final canopy cover higher than $60 \%$, with phacelia having the highest maximum coverage (79.9\%). Thus, our results suggest that in spite of a potential delay in early growth, as in the case of vetch, this can be recovered without detriment for the final soil cover, provided that there is still sufficient growing time before winter (Teasdale et al., 2004) and favorable growth conditions in terms of rainfall. For aboveground biomass there was a wider range of species differentiation, although statistically not significant, with phacelia $\left(1577 \mathrm{~kg} \mathrm{ha}^{-1}\right)$ and mustard $\left(1450 \mathrm{~kg} \mathrm{ha}^{-1}\right)$ at the higher end, and rye $\left(907 \mathrm{~kg} \mathrm{ha}^{-1}\right)$ and vetch $\left(859 \mathrm{~kg} \mathrm{ha}^{-1}\right)$ at a low level of dry matter production. This shows that, in contrast to its soil coverage, vetch obviously did not recover its initially delayed growth in terms of biomass accumulation.

Furthermore, a delayed early canopy coverage can be a substantial disadvantage concerning avoidance of runoff and erosion irrespective of the height of final ground cover. Assuming a lower threshold of 30\% ground cover (Quinton et al., 1997), mustard achieved this value 28 days after sowing, phacelia 35 , rye 37 and vetch only 52 days after sowing, respectively.

In the case of sufficient soil moisture for fast germination, as occurred in 2005, crops showed a homogeneous 
establishment. In this year water-limiting conditions developed during a prolonged dry period in autumn. This led to a differentiation in maximum cover $\left(\mathrm{y}_{\max , \mathrm{WJ}}\right)$ as well as a final decrease in canopy coverage $\left(\mu_{\min }\right)$ between the cover crop species (Tab. II).

Phacelia and rye were those species less tolerant to the 2005 rainfall pattern with dry conditions during the main growing period. Both achieved a low $\mathrm{y}_{\max , \mathrm{WJ}}$ below 50\%. The rapid canopy decrease $\left(\mu_{\min }\right)$ shows premature leaf senescence and abscission due to the low autumn rainfalls.

Parameters describing the increasing branch of the growth curve to the year-specific maximum value, i.e. $\mathrm{k}_{\mathrm{WJ}}$ and $\mathrm{t}_{\max , \mathrm{WJ}}$, did not differ significantly between the species in 2005. However, the lower $y_{\max , W J}$ of phacelia and rye led to a longer time to reach the threshold of $30 \%$ soil surface cover, which was reached 19 days after sowing by vetch, 22 by mustard, 30 by rye and 39 by phacelia, respectively.

For phacelia, to our knowledge there are no detailed studies concerning its susceptibility to drought. The observed canopy reduction under dry conditions was probably related to a limited plasticity in root penetration to depth (cf. Sect. 3.5). Rye is generally considered a cover crop that provides high soil cover and tolerance to dry conditions (e.g. Ingels et al., 1998; Sattell et al., 1998). This contradicts the low canopy cover and biomass observed in both years in our study. The erectophile leaf orientation of the monocotyledonous rye compared to more planophile dicotyledonous leaves may result in a lower canopy cover. Furthermore, we observed brown rust infection of the rye plants in both years. This might have negatively affected both photosynthetic capacity as well as water-use efficiency (Paul and Ayres, 1984). The low canopy cover in 2005 also corresponded to a very low biomass of rye $\left(712 \mathrm{~kg} \mathrm{ha}^{-1}\right)$ compared with the other cover crops. Phacelia was at an intermediate biomass level with $1135 \mathrm{~kg} \mathrm{ha}^{-1}$, similar to mustard $\left(1415 \mathrm{~kg} \mathrm{ha}^{-1}\right)$, in spite of the lower maximum canopy cover

Vetch and mustard both performed well under the dry autumn conditions in 2005 with a high canopy cover. Their tolerance to water shortage is also reflected in a lower $\mu_{\min }$ compared with phacelia and rye. Vetch also showed a dry matter accumulation significantly superior to all other species in this year $\left(2338 \mathrm{~kg} \mathrm{ha}^{-1}\right)$. These findings are in agreement with observations reported by Clark (2007) on hairy vetch, and by Gan et al. (2007) on mustard, who mentioned a comparatively high tolerance to water stress for these two species.

\subsection{Comparison of year sensitivity in canopy coverage of individual cover crops}

Cover cropping also requires that species are sufficiently stable in the desired growth traits under situations of different rainfall distribution and water availability. This was assessed by the sum of squares reduction test (cf. Eq. (4)). This test reveals which stable growth function parameters were shared over both years, and those parameters with high year variability under the different weather conditions. Vetch shared the Gompertz model in both years and was compared using the
Table III. Results of the sum of squares reduction (SSR) test for canopy cover models. Parameters/parameter sets indicate those model parameters which need to be given a year-specific value in order to achieve a non-significant difference to the full model case where all parameters have year-specific values.

\begin{tabular}{lccc}
\hline & $\begin{array}{c}\text { Parameters / } \\
\text { parameter sets }\end{array}$ & $\mathrm{F}$ & $P$ \\
\hline Phacelia & $\mathrm{y}_{\max , \mathrm{WJ}}$ & 3.42 & 0.07 \\
Vetch & $\mathrm{t}_{\max , \mathrm{G}}$ & 4.68 & 0.06 \\
& $\mu_{\min }+\mathrm{k}_{\mathrm{WJ}}$ & 1.90 & 0.40 \\
Rye & $\mu_{\min }+\mathrm{t}_{\max , \mathrm{WJ}}$ & 1.04 & 0.31 \\
& $\mathrm{k}_{\mathrm{WJ}}+\mathrm{t}_{\max , \mathrm{WJ}}$ & 1.75 & 0.23 \\
Mustard & $\mathrm{t}_{\max , \mathrm{WJ}}$ & 3.08 & 0.09 \\
\hline
\end{tabular}

Gompertz parameters. The other cover crops were evaluated using the Werker \& Jaggard model parameters.

Table III shows the F- and $p$-values of the sum of squares reduction test. At the given $p$-values the reduced model does not differ significantly from the full model. At this stage, the parameters/parameter sets indicated in Table 3 have a yearspecific value, while all other parameters of the respective growth functions (Eqs. (1) and (2)) share a common value in both years. Growth parameters having a common value express stability in the respective trait in spite of the different rainfall availability of the two years.

In case of phacelia, a year specific $Y_{\max }$ was required. The maximum canopy cover of phacelia was highly dependent on yearly growth conditions, being reduced from $79.9 \%$ in 2004 to only $47.0 \%$ in 2005 by a lack of rainfall during the period of major biomass growth. The dynamics of growth, as expressed by the growth rate and the time to reach the year-specific maximum cover, were less variable in response to the climatic conditions.

Vetch and mustard, on the other hand, were less variable concerning their maximum ground cover before the end of the growing season. The differing weather conditions affected more the temporal dynamics expressed in the $t_{\max }$ parameters of the two models. For vetch $t_{\mathrm{max}, \mathrm{G}}$ changed from 48 days in 2004 to 22 days in 2005 . This indicates the early growth sensitivity due to delayed germination and reduced early growth vigor under the dry sowing conditions of 2004. For mustard it shows some year-specific effect on the time to attain maximum soil cover ( $\left.\mathrm{t}_{\mathrm{max}, \mathrm{WJ}}\right)$, being 74 days in 2004 and only 46 days in 2005 , respectively. Plants often shorten their vegetative growth period under water stress (e.g. Bernier and Périlleux, 2005), which was apparently the case for mustard in 2005, already reaching its maximum at the beginning of October. However, from the point of view of soil protection, annual variability is more critical if it occurs during the early stages, as in the case of vetch, when canopy cover is still low (Quinton et al., 1997). Mustard therefore can be regarded as a reliable cover crop providing a stable high cover of more than $70 \%$. Its high growth rate guarantees a fast initial coverage of the soil surface. Haramoto and Gallandt (2004), reviewing cover crop use for weed control, also pointed out that the fast soil coverage is a general strength of Brassica cover crops. 


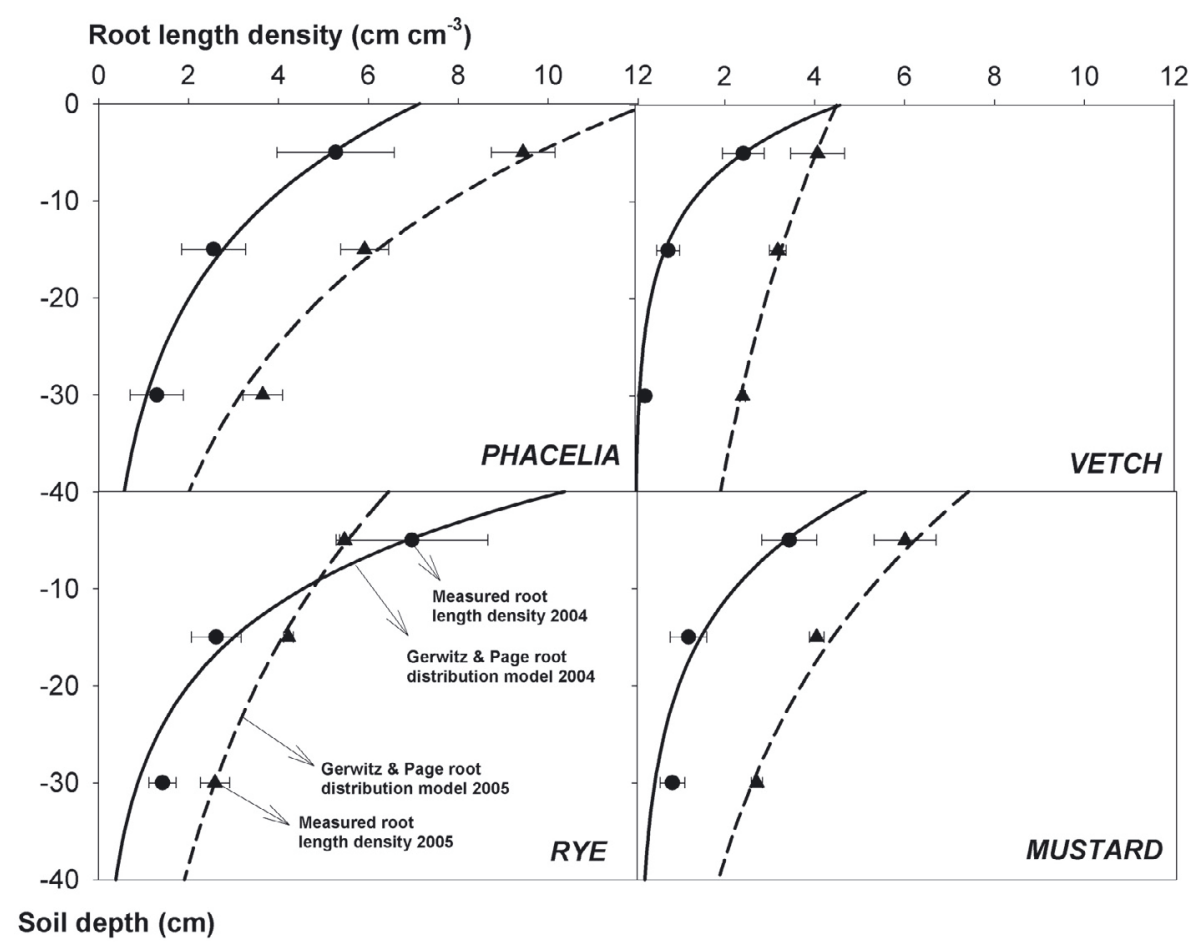

Figure 3. Root length density (RLD) means, standard errors and fitted Gerwitz \& Page root distribution functions. Highest surface near RLD (parameter $\mathrm{L}_{0}$ ) was achieved by rye (2004) and phacelia (2005). Roots were more concentrated in the upper layer in 2004, while in 2005 decrease in RLD with depth (parameter a) was less.

Rye showed a higher variability in its canopy growth dynamics in the two years than the other cover crops. The lowest difference from the full model was obtained with year-specific values for $\mathrm{k}_{\mathrm{WJ}}$ and $\mu_{\min }$. Only the maximum canopy coverage was stable over both years, although on quite a low level. This high variability in growth dynamics and a generally low maximum coverage would thus discourage the use of a rye monoculture for soil surface protection.

Under the semi-arid conditions at the site biomass growth of the cover crops was generally lower compared with values indicated in the literature for Central Europe (Lütke Entrup, 1986). We consider water to be the main limiting factor at the site. The distinct effects on the investigated cover crop species depending on the timing of water stress were shown clearly. Some additional influence of different intra-specific reactions of the species to the given nutrient status of the soil cannot be excluded. However, it should be of minor importance because of the generally high nutrient status of the chernozem soil and the nutrient input via the conventionally fertilized cash crops.

\subsection{Rooting pattern of cover crops}

Cover crop rooting traits contribute essentially to their agroenvironmental functions (e.g. Thorup-Kristensen, 2001). The root system also ensures sufficient water and nutrient supply for a stable cover crop growth. We described the cover crop species by root distribution function parameters of the Gerwitz $\&$ Page model (Eq. (3)). They provide two advantages for our
Table IV. Estimated parameter values (with standard errors in parentheses) of the Gerwitz \& Page model for root length density distribution of cover crops. For significant effects in the ANOVA at $P<0.05$, comparison of means is indicated by lower-case letters. Those species sharing the same letters are not significantly different.

\begin{tabular}{lcccc}
\hline & \multicolumn{2}{c}{2004} & \multicolumn{2}{c}{2005} \\
\cline { 2 - 5 } & $\mathrm{L}_{0}\left(\mathrm{~cm} \mathrm{~cm}^{-3}\right)$ & $\mathrm{a}(-)$ & $\mathrm{L}_{0}\left(\mathrm{~cm} \mathrm{~cm}^{-3}\right)$ & $\mathrm{a}(-)$ \\
\hline Phacelia & $7.2(1.8) \mathrm{ab}$ & $-0.075(0.021)$ & $12.2(1.2) \mathrm{a}$ & $-0.040(0.008)$ \\
Vetch & $4.9(1.6) \mathrm{b}$ & $-0.128(0.055)$ & $4.6(1.0) \mathrm{b}$ & $-0.022(0.013)$ \\
Rye & $10.6(2.2) \mathrm{a}$ & $-0.087(0.026)$ & $6.6(1.0) \mathrm{ab}$ & $-0.029(0.011)$ \\
Mustard & $5.2(2.3) \mathrm{b}$ & $-0.090(0.035)$ & $7.4(1.1) \mathrm{ab}$ & $-0.034(0.012)$ \\
\hline
\end{tabular}

purpose. Its first model parameter $\left(\mathrm{L}_{0}\right)$ captures the intensity of rooting near the soil surface. This allows a good characterization of the cover crops' potential contribution to soil structure stabilization in the uppermost soil layer. The second parameter (a) describes the decrease in rooting density with depth and points to the plants' access to water and nutrients from deeper soil layers. It could therefore provide a background for the interpretation of species' aboveground performance and stability. Measured root length density and distribution functions are shown in Figure 3; estimates of the corresponding Gerwitz \& Page parameters are given in Table IV.

Analysis of variance of the Gerwitz \& Page model parameters revealed major species differentiation in near-surface root length density $\left(\mathrm{L}_{0}\right)$. In both years vetch had the lowest value for $\mathrm{L}_{0}$. The low $\mathrm{L}_{0}$ of vetch is in agreement with observations 
Table V. Results of the sum of squares reduction (SSR) test for the root model. Parameters/parameter sets indicate those model parameters which need to be given a year-specific value in order to achieve a non-significant difference to the full model case where all parameters have year-specific values.

\begin{tabular}{lccc}
\hline & $\begin{array}{c}\text { Parameters / } \\
\text { parameter sets }\end{array}$ & F & $P$ \\
\hline Phacelia & $\mathrm{L}_{0}$ & 0.45 & 0.52 \\
Vetch & $\mathrm{a}$ & 1.41 & 0.26 \\
Rye & $\mathrm{a}$ & 0.01 & 0.97 \\
Mustard & - & 2.20 & 0.16 \\
& $\mathrm{~L}_{0}$ & 1.28 & 0.28 \\
& $\mathrm{a}$ & 0.36 & 0.56 \\
\hline
\end{tabular}

of Kutschera et al. (2009) for several legume root systems which show comparatively large root diameters, but less intense rooting of the soil. The cover crop species with highest $\mathrm{L}_{0}$ were rye in 2004 and phacelia in 2005. Mustard differed significantly to rye only in 2004. In 2005 mustard also had an intense near-surface rooting, but without significant differences from either phacelia or rye. Liu et al. (2005) demonstrated that the intense rooting of non-leguminous cover crops had a particularly large effect on the improvement of aggregate stability. In their review, Zuazo and Pleguezuelo (2008) referred to intense topsoil rooting as a main contribution to erosion control, which confirms the findings of Sarrantonio and Gallandt (2003) for rye.

The decay parameter a of the Gerwitz \& Page model showed a large small-scale variability and did not differ significantly between species. It mainly reflected the general influence of the year, revealing a typical plant root response to drought: under conditions of regular rainfall during the vegetation period (2004) roots concentrate near the surface and sharply decrease with depth $\left(\mathrm{a}_{\text {mean }}=0.10\right)$. By contrast, irregular rainfall with prolonged dry periods (2005) fosters deep root growth to improve water uptake (e.g. Kage et al., 2004). This is expressed in a lower average value of a (0.03). Rooting densities tend from an exponential to a more linear decrease with depth.

Table $\mathrm{V}$ shows the results for root parameter sensitivity to the year for the individual cover crop species revealed by the sum of squares reduction (SSR) test.

Rye was insensitive to the year, i.e. even the totally reduced model with both parameters having common values in both years did not differ significantly from the full model where all parameters are year-specific. This stable intense rooting of rye emphasizes that the main agro-environmental contribution of this cover crop is related to its belowground traits, particularly considering the inferior aboveground growth that we found in our study.

Vetch required the integration of a year-specific value for the parameter a. This indicates a high plasticity in root proliferation to depth in response to soil moisture for this cover crop. The root systems of phacelia and mustard were satisfactorily described over the two years if a year-specific value is attributed to at least one parameter. For phacelia the respec- tive $P$-values suggested a higher year sensitivity in $\mathrm{L}_{0}$, and for mustard in the parameter a.

Root plasticity, as suggested for vetch and to a lower extent also for mustard, improves plant response to water stress (Bell and Sultan, 1999). This is reflected by the lower susceptibility of these crops to canopy reduction after the dry autumn period in 2005. The proliferation of their root system to deeper layers allowed a higher water uptake from the soil.

Those cover crop species with the highest density in nearsurface rooting (rye, phacelia) can be expected to have substantial benefits for soil stabilization and amelioration (aggregate stability, soil microbiological activity), although these crops are more susceptible to drought in their aboveground traits, as expressed in their high $\mu_{\min }$ in 2005.

\section{CONCLUSION}

Cover cropping is a widely used agro-environmental management practice in Europe. A detailed species description of cover crops, however, is still lacking. Our study demonstrates the use of quantitative parameters from growth and root distribution functions for an improved cover crop characterization. This approach was applied to the canopy cover and rooting pattern of four cover crop species (phacelia, vetch, rye and mustard) under semi-arid conditions. The obtained parameters were used to characterize the species in terms of plant traits relevant for erosion control. Two main distinctions in canopy cover among the species could be revealed from the function parameters: delay in early vigor after dry sowing conditions (captured by the parameter $t_{\max }$ ) and limitation of maximum coverage due to low autumn rainfall (expressed in the parameter $\left.y_{\max }\right)$. These main distinctive parameters could be obtained from the asymptotic Gompertz function. Using an extended function also enabled the assessment of the decrease in canopy cover in late growth stages. Vetch was most affected by dry sowing conditions in its early vigor. This could be shown by a $+45 \%$ increase in the time to attain maximum growth rate (parameter $t_{\max }$ ) compared with the other species. Phacelia was most susceptible to the lack of autumn rainfall, reducing maximum coverage (parameter $\mathrm{y}_{\max }$ ) by $-41 \%$. Root characterization using an exponential distribution function could capture species differences in near-surface root density $\left(\mathrm{L}_{0}\right)$ and decrease in rooting (a) with depth. Phacelia had the highest average $\mathrm{L}_{0}$ with $9.7 \mathrm{~cm} \mathrm{~cm}^{-3}$. Vetch had the lowest value for $\mathrm{L}_{0}$ $\left(4.6 \mathrm{~cm} \mathrm{~cm}^{-3}\right)$ but showed a high capacity of deep root allocation under dry autumn conditions (low decrease in parameter a). Mustard combined high parameter values for $\mathrm{y}_{\max }$ (mean: $76 \%$ ) and $\mathrm{L}_{0}$ (mean: $6.3 \mathrm{~cm} \mathrm{~cm}^{-3}$ ), a fast initial coverage, and stable growth performance over both years. Rye also showed stability in $\mathrm{y}_{\max }$ and $\mathrm{L}_{0}$. High values, however, were only obtained in $\mathrm{L}_{0}$ (mean $8.6 \mathrm{~cm} \mathrm{~cm}^{-3}$ ), while $\mathrm{y}_{\max }$ was low in both years (mean $55.1 \%$ ).

The results demonstrate that our growth function-based approach could provide an improved cover crop species description. The function parameters allowed a quantitative comparison among the species and an assessment of their growth stability under different environmental conditions. 
The species description proposed in this study provides the basis for further developments towards a multi-environment, multi-trait database of cover crops. For this purpose additional data from a wider range of soil and climatic conditions should be included in this approach and further parameters related to other agro-environmental targets should be defined, e.g. for organic matter input, nitrate leaching prevention or weed control. The availability of comprehensive quantitative parameter sets of cover crop characteristics will be an important contribution to management optimization and improved decision support.

\section{REFERENCES}

Bell D.L., Sultan S.E. (1999) Dynamic phenotypic plasticity for root growth in Polygonum: A comparative study, Am. J. Bot. 86, 807819.

Bernier G., Périlleux C. (2005) A physiological overview of the genetics of flowering time control, Plant Biotechnol. J. 3, 3-16.

Bodner G., Loiskandl W., Buchan G., Kaul H.-P. (2008) Natural and management-induced dynamics of hydraulic conductivity along a cover-cropped field slope, Geoderma 146, 317-325.

Böhm W. (1979). Methods of studying root systems, Ecological Studies 33, Springer-Verlag, Berlin Heidelberg.

Carof M., Tourdonnet S., Coquet Y., Hallaire V., Roger-Estrade J. (2007) Hydraulic conductivity and porosity under conventional and notillage and the effect of three species of cover crop in northern France, Soil Use Manage. 23, 230-237.

Clark A. (2007) Managing cover crops profitably, Sustainable agriculture network handbook series, bk. 9, 144.

Feddes R.A., Raats P.A.C. (2004) Parameterizing the soil-water-plant root system, in: Feddes R.A., de Rooij G.H., van Dam J.C. (Eds.), Unsaturated-zone modelling, Progress, challenges and applications, Kluwer Academic Publishers, pp. 95-144.

Foley M. (1999) Genetic approach to the development of cover crops for weed management, J. Crop. Prod. 2, 77-93.

Gan Y., Malhi S.S., Brandt S., Katepa-Mupondwa F., Kutcher H.R. (2007) Brassica juncea canola in the northern great plains: responses to diverse environments and nitrogen fertilization, Agron. J. 99, 1208-1218.

Gerwitz A., Page E.R. (1974) An empirical mathematical model to describe plant root systems, J. Appl. Ecol. 11, 773-781.

Hampl U. (1996) Gründüngung, Leopold Stocker Verlag, Graz-Stuttgart.

Haramoto E.R., Gallandt E.R. (2004) Brassica cover cropping for weed management: A review, Renew. Agr. Food Syst. 19, 187-198.

Himmelbauer M.L., Loiskandl W., Kastanek F. (2004) Estimating length, average diameter and surface area of roots using two different image analysis systems, Plant Soil 260, 111-120.

Ingels C.A., Bugg R.L., Thomas F.L. (1998) Cover crop species and descriptions, Chapter 2, in: Ingels C.A., Bugg R.L., McGourty G.T., Christensen L.P. (Eds.), Cover Cropping in Vineyards: A Grower's Handbook, University of California, Division of Agriculture and Natural Resources, Publication 3338, pp. 8-39.

Kage H., Kocher M., Stützel H. (2004) Root growth and dry matter partitioning of cauliflower under drought stress conditions: measurement and simulation, Eur. J. Agron. 20, 379-394.

Karcher D.E., Richardson M.D. (2005) Batch analysis of digital images to evaluate turfgrass characteristics, Crop Sci. 45, 1536-1539.

Kutschera L., Lichtenegger E., Sobotik M. (2009) Wurzelatlas der Kulturpflanzen gemäßigter Gebiete mit Arten des Feldgemüsebaues, DLG-Verlags-GmbH, Frankfurt am Main.
Liu A., Ma B.L., Bomke A.A. (2005) Effects of cover crops on soil aggregate stability, total organic carbon, and polysaccharides, Soil Sci. Soc. Am. J. 69, 2041-2048.

Lütke Entrup E. (1986) Feldfutter und Zwischenfruchtbau, in: Oehmichen J. Pflanzenproduktion, Band 2: Produktionstechnik, Paul Parey, pp. 508-565.

MacRae R.J., Mehuys G.R. (1985) Effect of green manuring on the physical properties of temperate-area soils, Adv. Soil Sci. 3, 71-94.

Meyer L.D., Dabney S.M., Murphree C.E., Harmon W.C., Grissinger E.H. (1999) Crop production systems to control erosion and reduce runoff from upland silty soils, T. ASAE 42, 1645-1652.

Paul N.D., Ayres P.G. (1984) Effects of rust and post-infection drought on photosynthesis, growth and water relations in groundsel, Plant Pathol. 33, 561-569.

Pegelow E.J., Taylor B.B., Horrocks R.D., Buxton D.R., Marx D.B., Wanjura D.F. (1977) The Gompertz function as a model for cotton hypocotyl elongation, Agron. J. 69, 875-878.

Piepho H.P., Büchse A., Richter C. (2004) A mixed modelling approach for randomized experiments with repeated measures, J. Agron. Crop Sci. 190, 230-247.

Quinton J.N., Edwards G.M., Morgan R.P.C. (1997) The influence of vegetation species and plant properties on runoff and soil erosion: results from a rainfall simulation study in south east Spain, Soil Use Manage. 13, 143-148.

Rinnofner T., Friedel J.K., de Kruijff R., Pietsch G., Freyer B. (2008) Effect of catch crops on $\mathrm{N}$ dynamics and following crops in organic farming, Agron. Sustain. Dev. 28, 551-558.

Robert N., Huet S., Hennequet C., Bouvier A. (1999) Methodology for choosing a model for wheat kernel growth, Agronomie 19, 405417.

Roush W.B., Branton S.L. (2005) A comparison of fitting growth models with a genetic algorithm and nonlinear regression, Poultry Sci. 84, 494-502.

Sarrantonio M., Gallandt E. (2003) The role of cover crops in North American cropping systems, J. Crop Prod. 8, 53-74.

Sattell R., Dick R., Karow R., Kaufman D., Hemphill D., Luna J., McGrath D. (1998) Oregon Cover Crops: Cereal Rye, Oregon State University Extension Service, EM 8694.

Schabenberger O., Pierce F.J. (2002) Contemporary statistical models fort he plant and soil sciences. Chapter 5. Nonlinear models, CRC Press, Boca Raton, Florida.

Schutter M.E., Dick R.P. (2002) Microbial community profiles and activities among aggregates of winter fallow and cover-cropped soil, Soil Sci. Soc. Am. J. 66, 142-153.

Teasdale J.R., Devine T.E., Mosjidis J.A., Bellinder R.R., Beste C.E. (2004) Growth and development of hairy vetch cultivars in the northeastern United States as influenced by planting and harvesting date, Agron. J. 96, 1266-1271.

Thorup-Kristensen K. (2001) Are differences in root growth of nitrogen catch crops important for their ability to reduce soil nitrate-N content, and how can this be measured? Plant Soil 230, 185-195.

Tsoularis A., Wallace J. (2002) Analysis of logistic growth models, Math. Biosci. 179, 21-55.

Vidal M., López A. (2005) Cover crops and organic amendments to prevent nitrate contamination under a wet climate, Agron. Sustain. Dev. 25, 455-463.

Werker A.R., Jaggard K.W. (1997) Modelling asymmetrical growth curves that rise and then fall: applications to foliage dynamics of sugar beet (Beta vulgaris L.), Ann. Bot. 79, 657-665.

Yin X., Goudriaan J., Lantinga E.A., Vos J., Spiertz H.J. (2003) A flexible sigmoid function of determinate growth, Ann. Bot. 91, 361-371.

Zuazo V.H.D., Pleguezuelo C.R.R. (2008) Soil-erosion and runoff prevention by plant covers. A review, Agron. Sustain. Dev. 28, 65-86. 